\title{
Investigation of PBDEs in Landfill Leachates from Across Canada
}

\author{
Monica N. Danon-Schaffer (Corresponding author) \\ Department of Chemical and Biological Engineering, University of British Columbia \\ 2360 East Mall, Vancouver, V6T 1Z3, Canada \\ ERM, 6th Floor, 1111 West Hastings Street, Vancouver, V6E 2J3, Canada \\ Tel: 1-778-628-0451_E-mail: Monica.danonschaffer@gmail.com \\ John R. Grace \\ Department of Chemical and Biological Engineering, University of British Columbia \\ 2360 East Mall, Vancouver, V6T 1Z3, Canada
}

Tel: 1-604-822-3121_E-mail: jgrace@chbe.ubc.ca

\begin{abstract}
Michael G. Ikonomou
Institute of Ocean Sciences. PO Box 6000. 9860 West Saanich Road, Sidney, BC, Canada V8L 4B2

Tel: 1-250-363-6804 E-mail: Michael.ikonomou@dfo-mpo.gc.ca
\end{abstract}

Received: December 31, 2013 Accepted: January 19, 2014

doi:10.5296/emsd.v3i1.4855 URL: http://dx.doi.org/10.5296/emsd.v3i1.4855

\begin{abstract}
Leachates from 27 landfills (e.g. planned disposal area) across southern Canada and 11 dump sites (e.g. unorganized disposal area) in the Canadian North were collected (2006) and analysed (2006-2008) for polybrominated diphenyl ethers (PBDEs). There was wide variability in the results, both in terms of the total PBDE concentrations and in the distribution of congeners. Northern sites tended to have lower concentrations than southern ones, but some northern levels were significant, despite the low population density and lack of industry in the north. The North could potentially act as a sink for PBDE contaminants because many organic compounds get deposited via air or water currents in the North even though they were not manufactured there.
\end{abstract}


Keywords: landfill leachate, Polybrominated diphenyl ethers (PBDEs), persistent organic pollutants, Canadian North

\section{Introduction}

Given the health risks of PBDEs and their widespread appearance, including "alarming" levels in marine mammals (Ikonomou et al. 2002b) and in Canada's far northern communities (Ikonomou et al. 2002a), mass balances are needed to indicate the sources, transfer and accumulation of the various congeners in air, water and soil (Macleod et al. 2010). Increasing concentrations in the environment and potential ecological and human health risks also require early implementation of best-management practices to restrain the spread of PBDEs. Studying the leachability of PBDEs from e-wastes (Ma et al. 2012) and examination of landfill sites to determine their fate and transport are logical starting points. Such factors as the nature and extent of PBDE contamination, potential mobility, bio-availability and cumulative amounts in vegetation, soil and drainage water are important. The spatial distribution of PBDE contamination around landfills could assist in determining the sources (Devanathan et al. 2012) and spread of PBDEs.

PBDE levels in the environment are increasing (Ikonomou et al. 2002a; Rayne et al. 2003a; Hites 2004a). Although the EU, Canada and some US states have banned, or are in the process of banning, some PBDEs (European Commission 2005; Peele 2006; Canada Gazette Part II. 2008; Environment Canada 2009), past usage and consumption of PBDEs suggest that even banned congeners will persist in the environment for decades. Moreover, the deca (-209) BDE congener, not yet banned because it is difficult to replace, will continue in production. However, recent developments in the Stockholm Convention reported a proposal to phase out deca-BDE (UNEP-POPS, 2013). PBDEs are also exponentially increasing in Northern Canada, doubling every 4 to 5 years. BDE-47 has been found to be the largest contributor (Ikonomou et al 2002a).

The vast majority of commercial products containing PBDE compounds (electronics, mattresses, polyurethane foam, vehicle interiors, etc.) eventually enter waste streams. Up to $85 \%$ of discarded electronic products are ultimately sent to landfills $(\sim 80 \%)$, with the rest incinerated (Alcock et al. 2003).

The study is intended to assist in filling gaps in mass balance models and in determining the fate and assessing the risk of disposal on land and in landfills. This builds on the results reported in Li et al (2012). The Canadian North was selected because landfills and dumpsites are relatively isolated there. The long term objectives of northern sampling were to investigate how PBDEs are entering and being transferred among landfill (dumpsite) leachates and soils in the Canadian North and in other parts of Canada. A second long term objective was to provide data from locations well removed from population and industries. Another aim was to provide better understanding of the leachability of PBDEs from e-wastes (Ma et al. 2012) and other PBDE-containing products, and the mobility of PBDEs in soils. To the best of our knowledge, this is one of the first Canadian studies to investigate PBDE congener patterns in aqueous media (leachate, effluent and background water). Waste 
material at the urban landfill ${ }^{1}$ was segregated into different parcels, one for each half-decade (5-year) interval, thus facilitating comparison of leachates from wastes added in different time periods (Danon-Schaffer, et al. 2013a, 2013b).

\subsection{Landfills}

Landfilling has been the most common way to dispose of municipal solid waste (MSW) in many countries for decades, intended to reduce environmental impacts to a minimum (Francois et al. 2006). Waste is normally landfilled in horizontal layers and then compacted mechanically. The composition of the waste deposited in a landfill is determined by the consumption habits and waste management systems of the community where it is located, as well as changes in product usage (e.g. introduction of plastics in the 1960s) (Sormunen et al. 2008). Daily cover at a landfill normally consists of soil layers and bottom ash from incineration operations, used to minimize transfer as dust into the air. Daily cover may vary and consist of auto-shredder residue and/or shredded upholstery (Petreas et al. 2005). Landfills store heterogeneous materials over time, compacted to a density of 800 to 1,000 $\mathrm{kg} / \mathrm{m} 3$ (Sormunen et al. 2008). The degree of compaction influences the aerobic decay, temperature, homogeneity and rates of settlement across the landfill site (Campbell 1993).

The final quality of the waste cover is significant to prevent contaminant release to the environment. Environmental management of leachate should include monitoring of leachate quality and quantity, as well as the receiving environment (Campbell 1993). A landfill should be designed to contain leachate collection and treatment, either internally or externally. Some release may occur, no matter how well engineered a landfill is (e.g. with impermeable liners and caps, leachate and gas collection systems).

The behaviour of landfilled PBDE-containing products is poorly understood. Increasing amounts of e-waste continue to enter final disposal streams as faster equipment replaces older devices. Most discarded electronic items enter landfills and/or incinerators for final disposal (RIS International Ltd. 2003; Puckett et al. 2005; UNEP 2005; Grossman 2006; Hileman 2006; US EPA 2007; Wong et al. 2007; US EPA 2008; Ni and Zeng 2009). In recent years (between 2004 and 2013), some provinces in Canada have developed regulations to enforce e-waste recycling and ban them from landfills (Alta. Reg 93/2004; BC 2007, SK, 2007, NS 2008, ON 2009, PEI, 2010, MB 2010, QC 2012). Sediments in the water surrounding landfill and sewage treatment facilities contain nanogram/gram range concentrations of PBDEs (Allchin et al. 1999; de Boer et al. 2003; Chen et al. 2013). Currently, there are few studies (Ma et al. 2012) quantifying the distribution of PBDEs in landfill soils and the mechanism of leaching of PBDEs from such sites.

\subsection{Leachate}

Leachate is produced from precipitation that falls on the landfill site and percolates through the waste. It can also come from moisture in the waste that is slowly released as more waste or cover is placed on top of the MSW. Compounds contained in the original waste, as well as products resulting from waste degradation, are present in the leachate. Degradation processes

\footnotetext{
${ }^{1}$ We are unable to identify the landfill because of its confidentiality provisions
} 


\section{Al Macrothink}

Environmental Management and Sustainable Development

ISSN 2164-7682 2014, Vol. 3, No. 1

are affected by site geometry, waste types and input rates, as well as weather and operational practices (Campbell 1993). In addition to anaerobic processes which affect leachate inside landfills, leachate composition may be influenced by redox reactions, oxygen-demanding biological degradation, volatilization, dilution, sorption, ion exchange and precipitation (Öman and Junestedt 2007).

Proper leachate management is critical for any landfill, given the potential for contamination of aquifers, groundwater and surface water (Campbell 1993). In engineered landfills, geo-membrane liners are typically placed on the bottom of the landfill to prevent leachate migration beyond designated boundaries. Collection pipes commonly carry the leachate out of the landfill to an external collection system for future treatment, to a wastewater treatment plant, or for direct discharge to a body of water (Camobreco et al. 1999; Sormunen et al. 2008).

Leachate quality depends on the age of the landfill, the stage of waste degradation, and the organic matter, chloride, heavy metals and other organic/inorganic compounds contained in the wastes (Sormunen et al. 2008). The easiest way to characterize leachate is by identifying the main waste decomposition phases in a MSW landfill, these being the acid and methanogenic phases (Spalvins et al. 2008).

\subsection{Previous Studies on PBDEs in Leachate}

Data on PBDEs in leachates are sparse. Öman and Junestedt (2007) characterized landfill leachates in Sweden for compounds not previously analysed, including PBDEs. Samples were collected adjacent to waste deposit areas to obtain representative samples that would either migrate to surrounding areas or be treated in a sewage treatment plant. Reported PBDE levels were low relative to most reported elsewhere (Li, et al, 2012; Kiddee, et al, 2013).

Oliaei (2005) conducted a leachate study in Minnesota to investigate PBDE contamination in five landfills and sewage treatment plants, finding a range of 24,620-260,420 pg/L total PBDEs in the landfills (Table 1). Osako et al. (2004) analysed leachate from seven municipal and industrial landfills in Japan that contained bulk waste material plus crushed e-waste. The concentrations of PBDEs in leachate varied widely among the seven landfills studied, with relatively high concentrations at landfills that contained large volume of organic material. Due to the hydrophobicity of PBDEs, their levels ( $<8$ to $50,000 \mathrm{pg} / \mathrm{L}$ ) could have been influenced by dissolved humic substances in the leachate (Osako et al. 2004). The ranges for major congeners analyzed in previous work are compared in Table 1. 
Table 1. Summary of previous PBDE concentrations in leachates $(\mathrm{pg} / \mathrm{L})$ from the literature.

\begin{tabular}{|c|c|c|c|c|c|}
\hline Reference & This project & Oliaei, 2005 & $\begin{array}{c}\text { Oman \& } \\
\text { Junestedt, } 2007\end{array}$ & $\begin{array}{c}\text { Osako et al, } \\
2004\end{array}$ & $\begin{array}{c}\text { Odusanya, et al, } \\
2008\end{array}$ \\
\hline Location & Canada-wide & Minnesota, USA & Sweden & Japan & South Africa \\
\hline Type of landfill & municipal & $\begin{array}{l}\text { municipal, } \\
\text { industrial, } \\
\text { demolition }\end{array}$ & municipal & $\begin{array}{l}\text { municipal and } \\
\text { industrial }\end{array}$ & municipal \\
\hline $\begin{array}{l}\text { Extraction } \\
\text { method }\end{array}$ & liquid-liquid & $\mathrm{N} / \mathrm{A}$ & liquid-liquid & liquid-liquid & liquid-liquid \\
\hline Type of sample & leachate - grab & leachate & leachate - grab & leachate & leachate - grab \\
\hline Filtered & yes & $\mathrm{N} / \mathrm{A}$ & $\mathrm{N} / \mathrm{A}$ & yes & $\mathrm{N} / \mathrm{A}$ \\
\hline Filter size & $0.7 \mu \mathrm{m}$ & $\mathrm{N} / \mathrm{A}$ & $\mathrm{N} / \mathrm{A}$ & $1 \mu \mathrm{m}$ & $\mathrm{N} / \mathrm{A}$ \\
\hline Solvent & $\begin{array}{c}\text { dichloromethane, } \\
\text { accelerated } \\
\text { solvent extraction } \\
\text { (ASE) }\end{array}$ & $\mathrm{N} / \mathrm{A}$ & $\begin{array}{l}\text { methylene } \\
\text { chloride }\end{array}$ & $\begin{array}{c}\text { dichloromethane, } \\
\text { Soxhlet with } \\
\text { toluene }\end{array}$ & $\begin{array}{c}\text { hexane, } \\
\text { dichloromethane, } \\
\text { petroleum ether, } \\
\text { acetone }\end{array}$ \\
\hline BDE-47 & BMDL-194,000 & $180-5,000$ & 1700 & $<8-<500$ & $1,470-9,800$ \\
\hline BDE-99 & BMDL-500,000 & $230-7,500$ & NA & $<8-1,800$ & $440-5,200$ \\
\hline BDE-100 & BMDL-100,000 & $50-1,550$ & 1100 & $<8-<500$ & $240-2,160$ \\
\hline BDE-154 & BMDL-81,700 & $20-870$ & 1 & $<8-1,200$ & $140-2,180$ \\
\hline BDE-207 & BMDL-21,300 & $140-1,500$ & 290 & NA & NA \\
\hline BDE-209 & BMDL-460,000 & $24,000-244,000$ & 1100 & $<800-<50,000$ & NA \\
\hline $\begin{array}{l}\sum \text { total of } 6 \\
\text { congeners } \\
\text { (range) }\end{array}$ & BMDL-1,357,000 & $24,620-260,420$ & $1-1,700$ & $<8-50,000$ & $2,290-19,340$ \\
\hline $\begin{array}{l}\text { Total PBDEs } \\
\text { (background } \text { sites) } \\
\text { sita }^{*}\end{array}$ & 56,538 & $\mathrm{~N} / \mathrm{A}$ & $\mathrm{N} / \mathrm{A}$ & $\mathrm{N} / \mathrm{A}$ & $\mathrm{N} / \mathrm{A}$ \\
\hline $\begin{array}{l}\text { Total PBDEs } \\
\text { (municipal }^{\text {landfills) }}{ }^{\star \star}\end{array}$ & 231,713 & 83,055 & 838 & 10,702 & 22,543 \\
\hline
\end{tabular}

In order to facilitate comparison and interpretation, only six congeners common to all jurisdictions are included in this table: BDE-47, $-99,-100,-154,-207$ and -209 .

\section{Field Study}

\subsection{Sampling}

A confidential letter was sent to 50 jurisdictions across southern Canada to request leachate samples for PBDE analysis. In the end, 27 of these landfills provided leachate samples from operating landfills and closed landfills still being monitored for groundwater quality. PBDE concentrations were analysed from these 27 samples, and total organic carbon (TOC) values (discussed below in Section 2.4) were obtained from 20 of them. All samples from southern Canada were obtained in September to November 2005 and April to June 2006. Individualized data were provided to all 27 respondents. Variables such as population served by the landfill, age of waste in contact with leachate, type of landfill (municipal, industrial, other), leachate collection method, $\mathrm{pH}$, and conductivity were recorded. Note that each location in southern Canada did its own sampling based on its own sampling protocol, chosen by the landfill operators. Hence, some variability was no doubt introduced by different 


\section{MInstitute Macrothink $_{\text {Int }}^{\text {Intis }}$}

sampling procedures, added to variability caused by different waste compositions and different landfilling procedures. Some variability may also be due to weather, such as recent rainfall or prolonged drought, as well as different dates of sampling.

All sampling in the three territories of northern Canada was carried out by the first author, ensuring a uniform sampling methodology, with details on the sampling protocol and procedures described in $\mathrm{Li}$, et al (2012). An initial field trip was made to three northern Canadian locations (Yellowknife, Iqaluit, and Cambridge Bay) during the summer of 2004. A second field trip to eleven landfill sites in the North, including all three locations visited previously, was completed during the summer of 2006. All sampling locations were identified with Global Positioning System (GPS) coordinates. A map indicating sample locations is shown in Figure 1. Leachate, background water and soil samples were collected during both trips to determine the concentrations of measurable PBDE congeners ${ }^{2}$. Sampling sites, types of sample collected, nature of the dumpsites, latitude/longitude and populations of the communities served are specified in the supplemental data. Note that none of these northern dumpsites had liners or covers, and that there was no need to withhold the locations of sampling sites in the north.

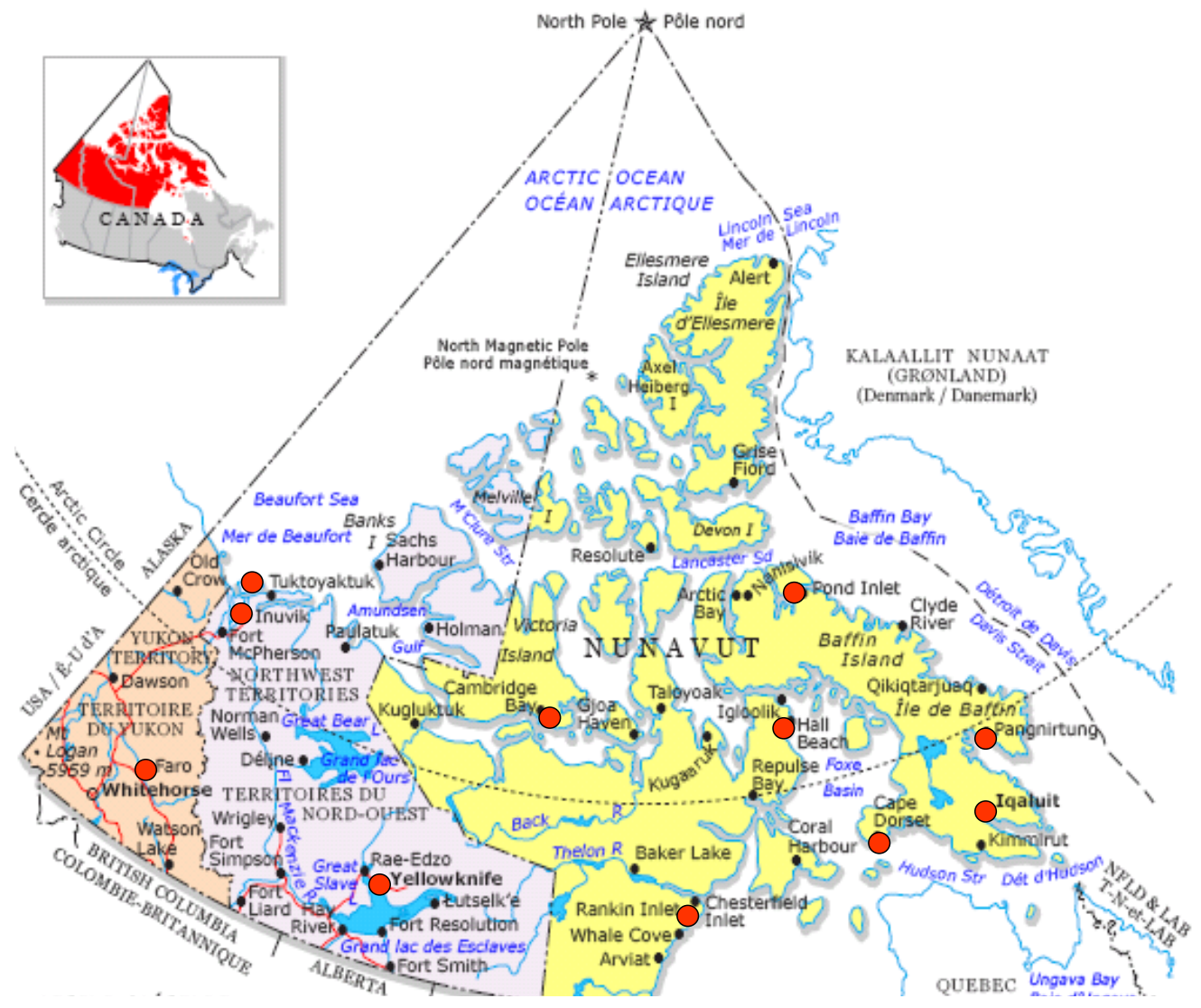

Figure 1. Map of Canada.

Large dots indicate communities where samples were collected

\footnotetext{
${ }^{2}$ Leachate and background data from 2004 are not included in the main analysis due to the limited number of samples collected and the wide variability. Because the 2006 samples could not be collected in precisely the same locations, no comparison is made between the 2004 and 2006 data.
} 
Due to the cost of sampling and analysis, replicate samples were available in only a small number of cases: a) leachate samples from Iqaluit, Hall Beach and Yellowknife, b) sewage effluent samples from Cape Dorset and Pangnirtung, and c) background water samples from Cambridge $\mathrm{Bay}^{3}$ (Danon-Schaffer, 2010). Raw data are compiled for individual congeners and in groups by bromine number, presented as total BDE groups, i.e. total tri-BDEs, total tetra-BDEs, etc.

All northern leachate samples were collected in 2.5 litre glass amber bottles previously washed with standard laboratory detergent (Alconox; White Plains, NY) and then rinsed in turn with distilled water, technical grade toluene, technical grade hexane, technical grade dichloromethane, and technical grade acetone. Most leachate samples were collected below the top of the groundwater table using Waterra ${ }^{\circledR}$ tubing, with a foot valve fitted at the bottom to dark amber glass bottles of $2.5 \mathrm{~L}$ volume. In cases where this was impossible, an amber glass bottle was submerged into leachate collection areas to fill the bottle. Effluent samples were collected at outfall points by placing the amber glass bottle directly under the flow. Samples were then stored at $4^{\circ} \mathrm{C}$ until analysis.

\subsection{Analytical Protocols}

Accurate analysis is especially difficult for BDE-209, requiring different clean-up and gas chromatography (GC) analysis than lower brominated congeners (de Boer 2004). All PBDE data presented here were subjected to comprehensive laboratory blank criteria for credibility, TOC, and, where possible, tested for consistency between two major laboratories (Danon-Schaffer, et al, 2013a). Most samples were re-analyzed to confirm PBDE levels and to assess factors affecting reproducibility, in particular to assess sub-sampling due to the lack of homogeneity because of significant loading of particles in the leachate samples. In addition, statistical analyses were performed on the replicate data. BDE-209 tended to have higher standard errors than the other congener groups (Danon-Schaffer 2010).

As explained by Danon-Schaffer (2010), PBDE concentrations were corrected by subtracting either one or two times the procedural blank values for aqueous samples. Many of the measured concentrations were found to be close to the detection limits (i.e. lab blanks), indicating barely detectable or even undetectable PBDE concentrations. Where BDE data had to be eliminated due to detection limits and blank corrections, these data are counted as zero when calculating totals and for plotting purposes. The PBDE aqueous data were compared with TOC (Danon-Schaffer, 2010) in an effort to better characterize the samples and to see whether there is any correlation between PBDE levels and TOC since PBDE molecules are likely to bind to, and travel with, other carbon-based molecules. In addition, aqueous samples that contained few particles were extracted via a simple liquid/liquid process which required minimum handling. Aqueous samples containing many particles required more extraction steps, beginning with filtration, followed by two different extraction paths. This in turn generated two procedural blanks, followed by centrifugation. The extra handling steps increased the potential for sample contamination as discussed elsewhere (Danon-Schaffer, et al 2013a).

\footnotetext{
${ }^{3}$ Also known as Ikaluktutiak
} 
Of the 60 congeners measured, only the nine "principal congeners", found in the highest concentrations, are discussed here. The tables in this paper provide data for the nine major congeners (BDE-47, -99, -100, -153, -154, -183, -206, -207, and -209) for each of the media investigated. The sum of these nine congeners constituted more than $90 \%$ of the total PBDE measured in most aqueous and soil samples.

The procedure to prepare the background samples for analysis differed from that of the leachate samples. These samples contained few particles, so they were liquid/liquid extracted. The corresponding procedural blanks were treated in the same manner. The potential for lab contamination through this process was greatly reduced due to the few steps involved in the extraction. In addition, consistency in the lab procedural blanks was important in order to provide accurate results, given the low concentrations of PBDEs in the samples.

\subsection{Total Organic Carbon (TOC) and Data Normalization}

TOC is a measure of the organic carbon in the particulate removed from the leachate samples. The raw PBDE data in the paper, even after procedural blank correction, were extremely variable. TOC is primarily influenced by particle size, analytical extraction efficiency and sampling/sub-sampling. Since particles rich in organic carbon have the greatest potential to bind PBDEs, and since PBDEs preferentially bind to particulates in water (Environment Canada. 2006), we measured the TOC concentration in the samples to examine whether there was any correlation between measured PBDE and TOC levels.

The samples were analysed for TOC on a Control Equipment Corporation (CEC) 240-XA Elemental Analyzer (Leeman Labs, Inc.), with standardization and procedural blank determination using a CAHN Electrobalance (Model 4400) (Knap et al. 1994). TOC content is the sum of the dissolved organic carbon (DOC) and particulate organic carbon (POC).

To determine whether there is a significant relationship between measured PBDE and TOC levels, BDE concentrations were correlated against TOC concentrations for each of the nine principal congeners. BDE-47 was plotted against TOC to illustrate this potential correlation. The Pearson coefficient, $\mathrm{R}$, varied between 0.46 and 0.97 , indicating large differences. When all samples are included in the correlation, the degree of correlation decreases in most congeners, as shown by the bottom row of Table 2. There is no apparent difference in the results from the samples that contained particulate and those that did not (Danon-Schaffer, 2010). Table 3 shows a much greater correlation between PBDEs and TOC levels if subsets of the data are taken with the highest measured PBDE concentrations (5, 6, 7 or 11 sites). There is good correlation between PBDE concentrations and TOC levels for most of the "principal" congeners in the samples where the highest PBDE concentrations were found, but the degree of correlation decreases as the degree of bromination increases.

One possible option considered was to normalize all the PBDE concentrations throughout the paper with the corresponding TOC concentration, in order to express the PBDEs as mass fractions of the organic carbon present. However, since the correlation with TOC was weak, except for the locations (Table 2) with the highest PBDE levels, the data are presented here in a dimensional (i.e. not normalized) manner. 


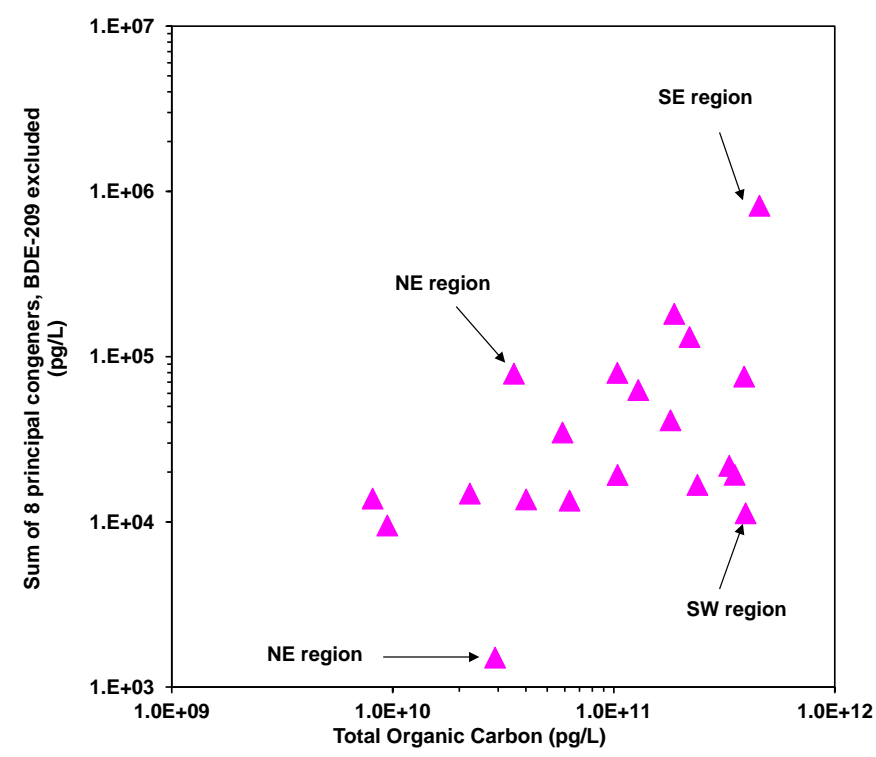

Figure 2. Leachate samples from landfill sites in major cities across Canada in 2005-2006.

Sum of the eight principal congeners (BDE-47, -99, -100, -153, -154, -183, -206, and -207). BDE-209 not included, from Canada-wide aqueous samples vs. total organic carbon (TOC) levels (pg/L). Outliers are indicated by arrows (Lab: DFO-IOS).

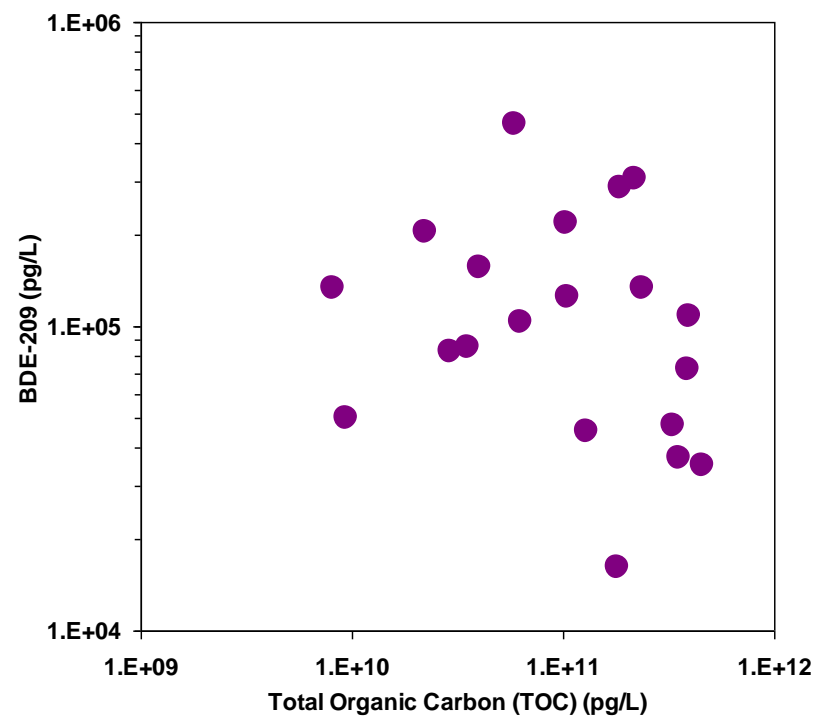

Figure 3. BDE-209 concentrations from Canada-wide aqueous samples vs. total organic carbon levels (TOC) (pg/L) (Lab: DFO-IOS).

Note that there are fewer points than sites analysed due to BMDL (below minimum detection level) concentration values. Arrows indicate samples that behaved differently from the rest because the sources of these samples were very different from one another.

As shown in Table 4, of the three locations (Hall Beach, Cape Dorset and Whitehorse WEP) had measurable concentrations of BDE-47, whereas the remainder were below minimum detection limits (BMDL). All sites had measurable BDE-209 concentrations, although three samples were BMDL for BDE-209. Hence, although analyzing BDE-209 presented particular 


\section{Ml Macrothink}

Environmental Management and Sustainable Development

ISSN 2164-7682

2014, Vol. 3, No. 1

challenges of lab contamination and interference, measurable values were obtained. Iqaluit and Hall Beach samples were re-extracted and the new values were averaged with those from the first extraction and are shown in Table 4.

Table 4. Major BDE congeners in leachate samples from northern Canada (pg/L)

\begin{tabular}{|c|c|c|c|c|c|c|c|c|c|c|c|c|c|}
\hline $\begin{array}{l}\text { Location } \\
\text { sampled }\end{array}$ & Description & BDE-47 & BDE-99 & BDE-100 & BDE-153 & BDE-154 & BDE-183 & BDE-206 & BDE-207 & BDE-209 & $\begin{array}{l}\Sigma 9 \text { main } \\
\text { congeners }\end{array}$ & Total BDEs & $\begin{array}{c}\text { BDE-209 as } \\
\% \text { of Total } \\
\text { BDEs }\end{array}$ \\
\hline $\begin{array}{l}\text { Yellowknife } \\
(\text { YELL-01) }\end{array}$ & Leachate from landfill & BMDL & BMDL & 502 & 214 & 157 & 207 & BMDL & BMDL & 22,152 & 23,232 & 26,755 & 83 \\
\hline Iqaluit (IQ1)* & West 40 landfill (current) & BMDL & BMDL & BMDL & BMDL & 40 & BMDL & BMDL & 1,508 & 83,137 & 84,685 & 84,756 & 98 \\
\hline $\begin{array}{l}\text { Cambridge Bay } \\
\text { (CAMBY4) }\end{array}$ & $\begin{array}{l}\text { Leachate and effluent } \\
\text { discharge to ocean }\end{array}$ & BMDL & BMDL & BMDL & BMDL & BMDL & BMDL & 509 & BMDL & 13,628 & 14,137 & 14,137 & 96 \\
\hline $\begin{array}{l}\text { Hall Beach } \\
(\mathrm{HB} 01)^{\star} \xi\end{array}$ & $\begin{array}{l}\text { Ponded water at municipal } \\
\text { dump, edge of town }\end{array}$ & 702 & 2,461 & 2,587 & 3,840 & 2,398 & 28,429 & 4,411 & 7,310 & 85,582 & 137,719 & 164,235 & 52 \\
\hline $\begin{array}{c}\text { Cape Dorset } \\
\text { (CD2) }\end{array}$ & Runoff from garbage dump & 4,117 & 1,132 & 483 & 141 & ND & BMDL & 1,605 & 886 & 49,764 & 58,128 & 59,253 & 84 \\
\hline $\begin{array}{l}\text { Whitehorse } \\
\text { (SWE-4B) }\end{array}$ & $\begin{array}{l}\text { Current leachate collection at } \\
\text { landfill }\end{array}$ & BMDL & BMDL & BMDL & 10 & BMDL & BMDL & 2,453 & 1,770 & 83,420 & 87,653 & 88,871 & 94 \\
\hline $\begin{array}{l}\text { Whitehorse } \\
\text { (WEP) }\end{array}$ & $\begin{array}{l}\text { War Eagle Pit, historical } \\
\text { leachate, } 25 \mathrm{~m} \text { depth }\end{array}$ & 6,199 & 1,990 & 407 & 277 & 167 & 806 & 934 & 2,420 & 103,873 & 117,073 & 150,090 & 69 \\
\hline $\begin{array}{l}\text { Inuvik } \\
\text { (INUVIK2) }\end{array}$ & $\begin{array}{l}\text { Downgradient from dump at } \\
\text { Finning Lake }\end{array}$ & BMDL & BMDL & BMDL & BMDL & BMDL & BMDL & BMDL & BMDL & BMDL & BMDL & BMDL & NA \\
\hline $\begin{array}{l}\text { Tuktoyaktuk } \\
\text { (TUK-2) }\end{array}$ & $\begin{array}{l}\text { Adjacent to main water body, } \\
\text { received leachate from dump } \\
\text { and discharges directly to } \\
\text { ocean }\end{array}$ & BMDL & BMDL & BMDL & BMDL & BMDL & BMDL & ND & ND & ND & BMDL & BMDL & NA \\
\hline $\begin{array}{l}\text { Tuktoyaktuk } \\
\text { (TUK-3) }\end{array}$ & $\begin{array}{l}\text { Ponded leachate at dumpsite, } \\
\text { subsequently drains to ocean }\end{array}$ & BMDL & BMDL & BMDL & BMDL & BMDL & BMDL & BMDL & BMDL & BMDL & BMDL & BMDL & NA \\
\hline
\end{tabular}

$\xi$ These samples were re-extracted. Procedural blank correction for the re-extracted batches corresponds to 2 times procedural blank correction for the first 6 congeners of the table

(corresponds to Cluster E described elsewhere, Danon-Schaffer, 2010) and to 1 time procedural blank extraction for the remaining 3 congeners (BDE-206, -207, and -209) (corresponds to Clu: elsewhere, Danon-Schaffer 2010). Values presented in this table were averaged with the first extraction.

One-time procedural blank correction, except where noted (corresponds to Clusters D and J described by Danon-Schaffer (2010). (Lab: DFO-IOS)

Compared to all other leachate samples, Hall Beach (HB-01) had a unique concentration profile (Table 4), with higher-brominated congeners having elevated concentrations. One reason may be that this leachate ponded in a low lying area, allowing the molecules to potentially bioaccumulate. The Cape Dorset (CD-2) sample was also collected in a ponded area where the leachate may have been more concentrated. The Whitehorse (WEP) sample was collected from a depth of approximately $25 \mathrm{~m}$. That location is known to contain old leachate (20 years or more), so that high PBDE concentrations are not surprising, given the heavy incorporation of PBDEs as a flame retardant in electronic and other products in the 1980s (Tasaki, et al. 2004; ENVIRON 2003). The volume of leachate in the Iqaluit landfill was much greater than at either Hall Beach or Cape Dorset.

\subsection{Distribution and Congener Patterns of PBDEs in Leachate}

The highest PBDE concentration in leachate was measured in Hall Beach HB-01 (164,235 $\mathrm{pg} / \mathrm{L})$ and Whitehorse, WEP $(150,090 \mathrm{pg} / \mathrm{L})$. The major PBDE congener measured in these leachate samples was BDE-209, ranging between 52 and $98 \%$ of the total, except for Inuvik (INUVIK2) and Tuktoyaktuk (TUK-2, TUK-3) (see Table 4). The major congeners were present in leachate samples from Hall Beach (HB-01), Cape Dorset (CD-2) and Whitehorse (WEP). Replicate samples were analysed for YELLO1, IQ1 and HB-01: three, six and two duplicates, respectively, increasing the reliability of these results. The highest concentration 


\section{MInstitute Machink $_{\text {Int }}$}

Environmental Management and Sustainable Development

ISSN 2164-7682

2014, Vol. 3, No. 1

of BDE-183, a major component of the Octa-BDE commercial product, was measured in HB-01 (28,429 pg/L). Large variations between the lowest and highest concentrations in these samples are likely due to a combination of factors, including diversity of materials entering the dumpsites, different community characteristics, differences in rainfall and soil permeability and analysis errors, especially when the levels are low.

The HB-01 and WEP samples may have contained all three commercial formulations (Penta, Octa and Deca-BDE), as all 9 principal congeners were present in measurable quantities. For CD-2 and Whitehorse (SWE-4B), the presence of the commercial Deca-BDE product is more apparent, as BDE-207 and -206 patterns are similar, and Deca-BDE is known to contain small amounts of these congeners. However, CD-2 was found to have approximately $7 \%$ of BDE-47, one of the more persistent congeners in the Penta-BDE product (typically between 28 and $30 \%$ by weight.) This may also indicate a degraded Penta-BDE formulation. Except for HB-01 and WEP, BDE-209 was the major contributor to the BDE concentrations in these leachate samples.

\subsection{Background Samples}

The background sample sites were chosen because they were likely to be free of contaminants (Iqaluit: IQAX-3 and IQ5W40; Pangnirtung: PANG3; Cape Dorset: CD1; Hall Beach: HB-02; Pond Inlet: PI-1; Cambridge Bay: CAMBY7 and CAMBY8; Inuvik: INUVIK1 and INUVIK2; Tuktoyaktuk: TUK-1; Rankin Inlet; and Whitehorse: WHT-PC). Most are drinking water sources for the communities in which they were drawn. In total, thirteen background water samples were collected. Most of these data (Table 5) were BMDL.

Table 5. Major BDE congeners found in background water samples from the Canadian North $(\mathrm{pg} / \mathrm{L})$

\begin{tabular}{|c|c|c|c|c|c|c|c|c|c|c|c|c|c|}
\hline $\begin{array}{l}\text { Location } \\
\text { sampled }\end{array}$ & Description & BDE-47 & BDE-99 & BDE-100 & BDE-153 & BDE-154 & BDE-183 & BDE-206 & BDE-207 & BDE-209 & $\begin{array}{l}\sum 9 \text { main } \\
\text { congeners }\end{array}$ & Total BDEs & $\begin{array}{c}\text { BDE-209 } \\
\text { as } \% \text { of } \\
\text { Total } \\
\text { BDEs }\end{array}$ \\
\hline Iqaluit (IQAX-3) & Apex Flats & BMDL & BMDL & BMDL & BMDL & $\mathrm{ND}$ & BMDL & BMDL & BMDL & 62,083 & 62,083 & 62,083 & 100 \\
\hline $\begin{array}{c}\text { (Igaluit } \\
\text { (IQ5W40) }\end{array}$ & Upgradient from W40 landfill (currer & BMDL & BMDL & BMDL & BMDL & ND & BMDL & BMDL & BMDL & BMDL & BMDL & BMDL & N/A \\
\hline $\begin{array}{l}\text { Pangnirtung } \\
\text { (PANG3) }\end{array}$ & Upstream river, drinking water sourc & BMDL & BMDL & BMDL & BMDL & ND & BMDL & BMDL & BMDL & BMDL & BMDL & BMDL & BMDL \\
\hline $\begin{array}{l}\text { Cape Dorset } \\
\text { (CD1) }\end{array}$ & Tellik Inlet (Arctic Ocean) & BMDL & BMDL & BMDL & BMDL & ND & BMDL & 447 & 659 & 32,929 & 34,035 & 34,035 & 97 \\
\hline $\begin{array}{l}\text { Hall Beach (HB- } \\
\text { 02) }\end{array}$ & $\begin{array}{l}\text { Drinking water source for town, lake } \\
\text { adjacent to DEW line clean up and } \\
\text { close to airport }\end{array}$ & BMDL & BMDL & BMDL & BMDL & BMDL & BMDL & BMDL & BMDL & 6,391 & 6,391 & 6,391 & 100 \\
\hline $\begin{array}{l}\text { Pond Inlet (P1- } \\
\text { 1) }\end{array}$ & $\begin{array}{l}\text { Primary water source for town, } \\
5 \mathrm{~km} \text { away }\end{array}$ & BMDL & BMDL & BMDL & BMDL & BMDL & BMDL & BMDL & BMDL & BMDL & BMDL & BMDL & N/A \\
\hline $\begin{array}{c}\text { Cambridge Bay } \\
\text { (CAMBY 7) }\end{array}$ & Background water & BMDL & BMDL & BMDL & BMDL & BMDL & BMDL & BMDL & BMDL & BMDL & BMDL & BMDL & $\mathrm{N} / \mathrm{A}$ \\
\hline $\begin{array}{c}\text { Cambridge Bay } \\
(\text { CAMBY B)* }\end{array}$ & Towards Mt. Pelly, out of town & BMDL & BMDL & BMDL & BMDL & BMDL & BMDL & BMDL & BMDL & BMDL & BMDL & BMDL & BMDL \\
\hline $\begin{array}{c}\text { Inuvik } \\
\text { (INUVIK1) }\end{array}$ & "Road's End" golf course & BMDL & BMDL & BMDL & BMDL & BMDL & BMDL & BMDL & 334 & 15,843 & 16,177 & 16,177 & 98 \\
\hline $\begin{array}{c}\text { Inuvik (INUVIK } \\
3 \text { ) }\end{array}$ & Boot Lake & BMDL & BMDL & BMDL & ND & ND & BMDL & BMDL & BMDL & BMDL & BMDL & BMDL & BMDL \\
\hline $\begin{array}{l}\text { Tuktoyaktuk } \\
\text { (TUK-1) }\end{array}$ & $\begin{array}{l}\text { Former drinking water source for } \\
\text { town, "Water Lake" }\end{array}$ & BMDL & BMDL & BMDL & 88 & 13 & 848 & 142 & 421 & BMDL & 1,512 & 1,512 & BMDL \\
\hline $\begin{array}{l}\text { Nipissar Lake } \\
\text { (Rankin Inlet) }\end{array}$ & Background source & BMDL & BMDL & BMDL & BMDL & BMDL & BMDL & $N / A$ & N/A & $\mathrm{N} / \mathrm{A}$ & BMDL & BMDL & $N / A$ \\
\hline $\begin{array}{l}\text { Whitehorse } \\
(\text { WHT-PC) })^{\xi}\end{array}$ & $\begin{array}{l}\text { Upstream at Porter Creek, prior to } \\
\text { entering landfill }\end{array}$ & 4,610 & 350 & 1,508 & 127 & 165 & 725 & 2,849 & 2,378 & 204,219 & 216,929 & 219,029 & 93 \\
\hline
\end{tabular}




\section{Macrothink}

Environmental Management and Sustainable Development

ISSN 2164-7682

2014, Vol. 3, No. 1

One time procedural blank corrected except where noted (corresponds to Clusters D and J described elsewhere (Danon-Schaffer 2010)). (Lab: DFO-IOS)

No clear pattern emerges from the samples that reported measurable BDE concentrations, except for Cape Dorset (CD1) and Whitehorse (WHT-PCT). A profile similar to the Deca-BDE commercial product is observed for these two samples, with BDE-209, comprising 93-97\%, BDE-206 with 1.3\%, and BDE-207 ranging from 1.08 to $1.93 \%$. The profile for Tuktoyaktuk (TUK-1) may indicate degradation of Deca-BDE to produce highand mid-level congeners (i.e. BDE-153, -154, -183, -206, and -207). The concentrations from Pangnirtung, the only community to operate a sewage treatment plant in the northern Canada, were high relative to the other sites. Note that each sample represents a point in space and time and must not be regarded as representative of an entire region.

The total PBDE concentrations from the sum of the nine principal congeners in the background water samples constitute all of the PBDEs measured. Only five of the 13 locations analysed showed measurable concentrations of BDE-209. Its appearance may be related to its greater persistence and being carried north via atmospheric currents and/or by water as fine particulates.

Table 5 indicates that the background water sample from Whitehorse (WHT-PC) was the only sample to show measurable levels of all BDE congeners after procedural blank correction. Given the extremely low solubility of deca-BDE in water, the measured concentrations likely reflect fine particulates in the water, but it is also possible that the solubility could have been increased by humic substances or other components in the water.

\section{Results and Discussion - Southern Canada}

Complete data from the different jurisdictions where leachate was collected are presented in the supplemental data section. The names of the cities and towns are withheld to comply with the terms of the invitations to participate in the study. Instead, sample locations are identified by an unrelated uppercase letter. The raw data, procedural blank correction and final values are listed in the supplemental data section.

The total PBDE measured concentrations varied substantially from location to location, ranging from $969 \mathrm{pg} / \mathrm{L}$ to $867,805 \mathrm{pg} / \mathrm{L}$, as shown in Table 2. BDE-209 was the major congener of those measured. Major congeners detected in the leachate samples of all sites included those prominent in the Penta commercial mixture (BDE-47, -99, -100, -153, and -154), as seen in Figure 4. Thirteen sites (out of a possible 27) indicated BDE-209 values between 60 and $92 \%$ of total PBDE concentrations. Five sites not included in Figure 4 are excluded because their congener values were BMDL after procedural blank correction. 


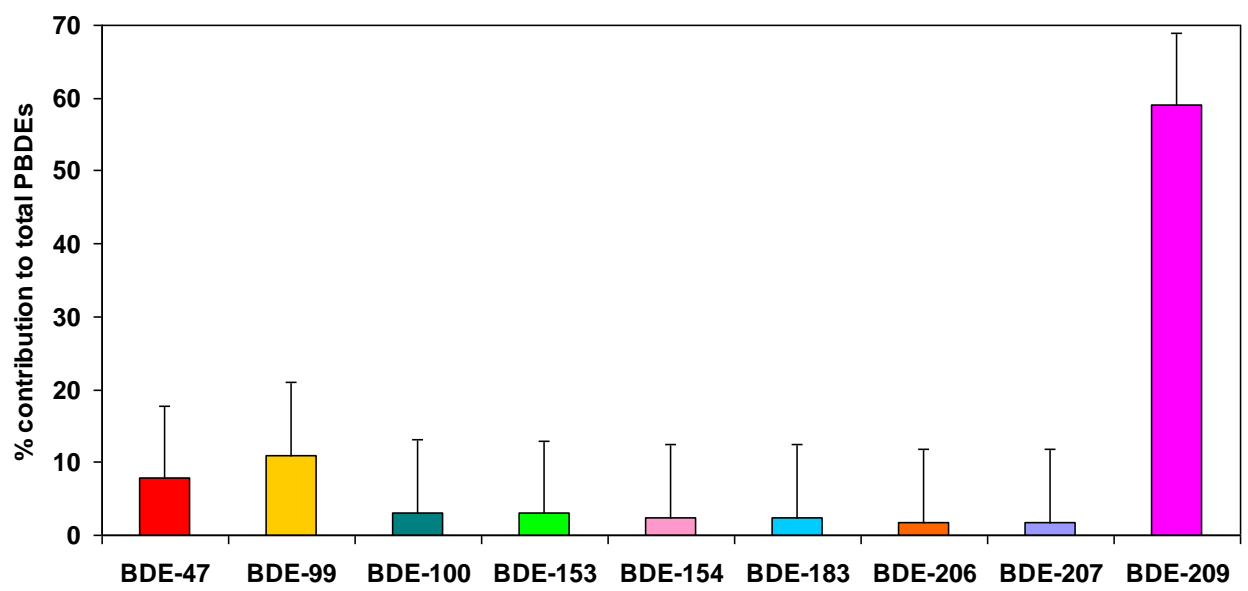

Figure 4. Mean principal BDE congeners in southern Canada leachate relative to total PBDEs. Five sites that fell below method detection limits for all congeners after procedural blank correction are excluded from the averages.

\subsection{BDE Ratios Compared with Commercial Product}

The dominant BDE congeners in the Penta-BDE commercial product are BDE-47, -99 and -100 (Stapleton et al. 2005). The ratios of concentrations of BDE-47 to BDE-99 and of BDE-47 to BDE-100 are plotted in Figures 5 and 6, respectively, against total PBDE concentrations from leachate in landfills across southern Canada and compared to the corresponding ratios in the Penta-BDE commercial product. As observed in Figure 5, the BDE-47/BDE-99 ratio in the commercial Penta-BDE product DE-71 is 0.6, whereas in Figure 6 the BDE-47/BDE-100 ratio in the commercial Penta-BDE product DE-71 is 3.5. In each case, the same leachate samples collected exhibited ratios close to those of the commercial product shown by the dashed horizontal lines, except for samples with the lowest total PBDE concentrations (which are subject to the greatest uncertainty). This suggests that wastes from which the PBDEs originated contained the Penta-BDE product, discarded recently enough for the congener pattern to still be recognizable.

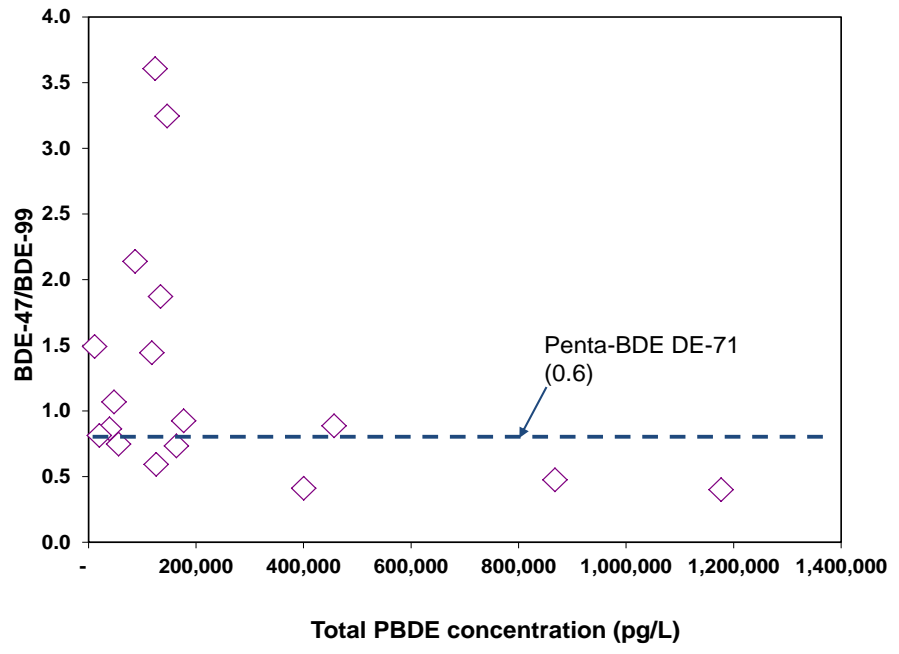

Figure 5. Ratio of BDE-47 to BDE-99 measured in landfill leachates from across southern Canada vs. total PBDE concentration. 


\section{Macrothink}

Environmental Management and Sustainable Development

ISSN 2164-7682

2014, Vol. 3, No. 1

Dashed line represents ratio in commercial Penta-BDE product, DE-71 (0.6) (Rayne and Ikonomou 2002). Points represent fifteen of the twenty samples. The other five samples were BMDL after procedural blank correction.

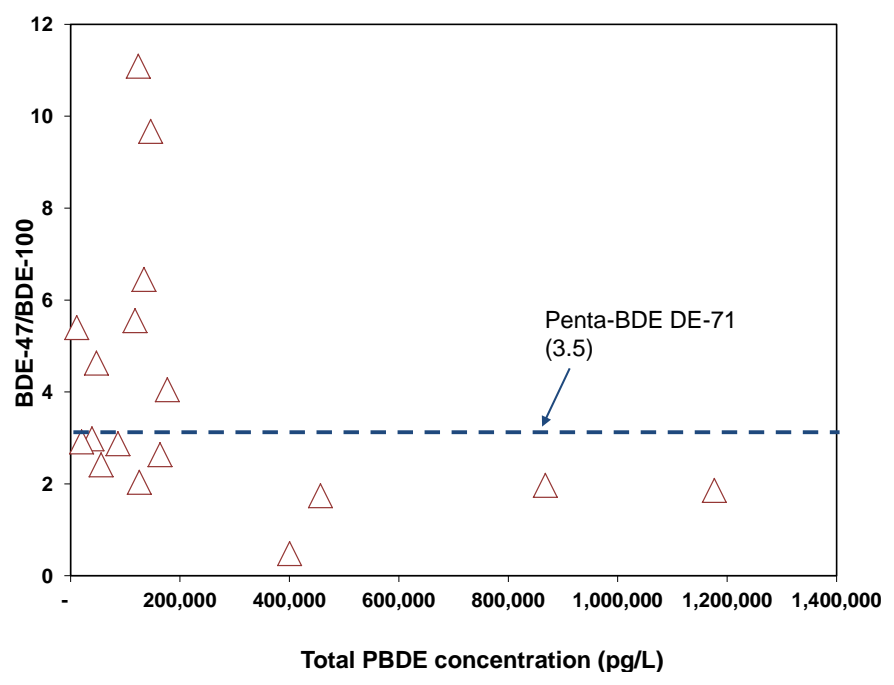

Figure 6. Ratio of BDE-47 to BDE-100 measured in landfill leachates from across southern Canada vs. the total PBDE concentration.

Dashed line represents ratio in commercial Penta-BDE product, DE-71 (3.5) (Rayne and Ikonomou 2002; ENVIRON 2003). Points represent fifteen of the twenty samples listed. The other five samples were BMDL after procedural blank correction.

Some studies have demonstrated that BDE congeners can debrominate as a result of exposure to UV rays (Eriksson et al. 2004; Söderström et al. 2004). However, the decomposition products were not identified in these papers. Stapleton et al. (2005) indicated that BDE-47 could be formed by the removal of a bromine atom from the BDE-99 congener. Note that BDE-47 could diffuse out of the treated product at a faster rate than BDE-99 because BDE-47 has a higher potential for long range transport relative to BDE-99 (Gouin and Harner 2003). Although BDE-100 was not mentioned in the Gouin and Harner (2003) study, its decomposition rate is expected to be comparable to that of BDE-99 given the structural similarity of these two congeners (Stapleton et al. 2005).

\subsection{Population as a Determinant of PBDE Concentrations in Landfill Leachate}

To create a larger data set, the southern Canada data are combined with the northern Canada data for the rest of this paper. For purposes of data presentation, Canada is divided into four quadrants: northwest, southwest, northeast, and southeast, with the dividing line between east and west taken as the Manitoba-Ontario border, whereas the division between north and south is the 60th parallel (coinciding with the northern boundaries of British Columbia, Alberta, Saskatchewan and Manitoba). Populations are 2006 census values.

In order to show the possible effect of population of the corresponding city/town, both principal congeners and total PBDE concentrations are considered. In addition, if the total PBDE concentrations are broken down into the major congeners discussed throughout this 
paper, BDE-209 is the one congener that shows up in the highest concentrations. As expected, there is a strong correlation $(\mathrm{R}=0.83)$ between population served and annual mass flow of wastes sent to the local landfill (tonnes/year). When the correlation of total PBDE concentrations to population is explored, the correlation coefficient is 0.26 , as shown in Table 6. This indicates some correlation between PBDEs in landfills and population served, presumably because larger centres tend to be bigger consumers of electronic products and other manufactured goods, as well as being located further south. However, the relationship also depends on how the waste is handled and on the sampling protocols. The small number of sites, variation in sampling procedures and general scatter probably account for the limited correlation with population.

Table 6. Pearson correlation coefficient of total PBDE concentrations vs. population and landfill tonnage $v s$. population

\begin{tabular}{|c|r|r|r|}
\hline Location & Population & $\begin{array}{c}\text { Landfill refuse } \\
\text { mass flow } \\
\text { (tonnes/yr) }\end{array}$ & \multicolumn{1}{|c|}{$\begin{array}{c}\text { Total PBDEs } \\
\text { (pg/L) }\end{array}$} \\
\hline T & 580,000 & $1,200,000$ & $1,139,532$ \\
F & 900,000 & 900,000 & 69,011 \\
U & $1,000,000$ & 740,000 & 23,719 \\
I & 100,000 & 250,000 & 108,165 \\
V & 120,000 & 165,000 & 147,749 \\
S & 500,000 & 163,000 & 148,244 \\
N & 21,000 & 160,000 & 170,775 \\
A & 380,000 & 160,000 & 853,568 \\
H & 86,000 & 156,000 & 57,237 \\
B & 110,000 & 100,000 & 119,796 \\
J & 48,000 & 80,000 & 143,788 \\
G & 73,000 & 67,000 & 151,082 \\
W & 46,000 & 47,000 & 25,480 \\
D & 28,000 & 40,000 & 468,563 \\
X & 32,000 & 40,000 & 27,755 \\
Y & 36,000 & 38,000 & 237 \\
Z & 25,000 & 26,000 & 16,643 \\
L & 21,000 & 25,000 & 117,288 \\
AA & 4,000 & 12,700 & 30,848 \\
P & 8,000 & 10,000 & 84,756 \\
BB & 20,000 & 10,000 & 26,755 \\
\hline Correlation coefficient of population to total PBDEs: 0.26 \\
Correlation coefficient of population to landfill refuse volume: 0.83 \\
\hline \multicolumn{4}{|r}{}
\end{tabular}

Approximate population from Statistics Canada 2006 census. Total PBDE concentrations are from our sampling data. Landfill tonnage data reported for each landfill are from 2005-06 ${ }^{5}$.

Possible correlations were also considered by quadrant and by combinations of quadrants. The mid-to-lower brominated congeners (BDE-47, -99, -100, -153- and -154) correlated best for the south (average $\mathrm{R}=0.42$ ) and west regions (average $\mathrm{R}=0.40$ ).

Although the PBDE concentrations were generally lower in the northern communities, some northern levels are similar to those of urban centres south of latitude 60 . The remaining southern samples were between one and three orders of magnitude higher in total PBDE concentrations than for northern Canada. It is important to put this into perspective. The

\footnotetext{
${ }^{5}$ Tonnage data was not available for Sites C, E, K, M, O, Q, or R.
} 


\section{Macrothink}

landfills examined were not homogeneous in terms of the types of materials disposed, depth, nor in sampling methodologies. These factors undoubtedly contributed to the observed scatter and limited correlations. However, as noted above, some correlation was found within the regions, indicating higher PBDE concentrations with higher refuse volume.

Total PBDEs are plotted against population in Figure 7. The outliers in this figure all correspond to populations less than 50,000. In Figure 8, concentrations of the BDE-47, -99 and -100 congeners are plotted against population, excluding the difficult-to-measure BDE-209. The data again suggest, albeit with considerable scatter, that a larger population tends to result in higher PBDE concentrations in leachate. The correlation appears to be better for BDE-47 than for BDE-99 or -100. Comparison of these two figures provides an indication of how much BDE-209 influences the total PBDE concentration.

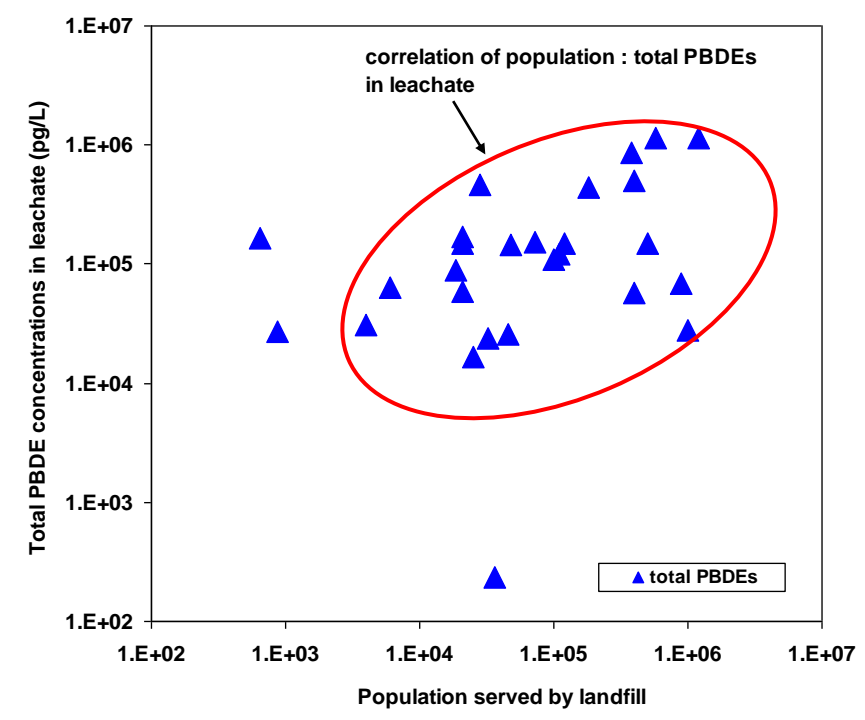

Figure 7. Total PBDE concentrations in leachate as a function of population served by landfill or dumpsite.

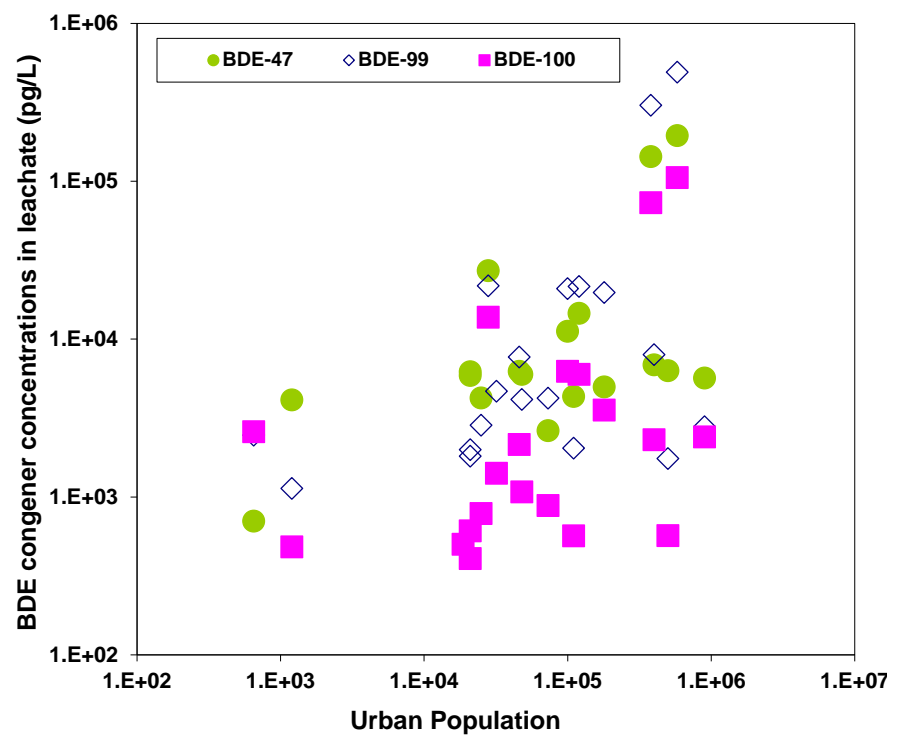

Figure 8. BDE-47, -99 and -100 congener concentrations as a function of population. 


\section{Macrothink}

Environmental Management and Sustainable Development

ISSN 2164-7682 2014, Vol. 3, No. 1

\subsection{Latitude as a Possible Determinant of PBDE Concentrations in Landfill Leachate}

Average and range of total PBDE concentrations are plotted for landfill leachate samples from southern and northern Canada in Figure 9. It is seen that the concentrations tend to be smaller for northern sites. As expected, there is a strong negative correlation between population and latitude, so that at least part of the north-vs.-south effect is due to the population effect discussed above. However, it is likely that lower concentrations in northern Canada than in southern Canada also reflect, to some extent, greater use of plastics and electronic products in the south, and limited north-south atmospheric and water-based dispersion. When data are considered by quadrant, northeast is somewhat higher than northwest, and southwest higher than southeast.

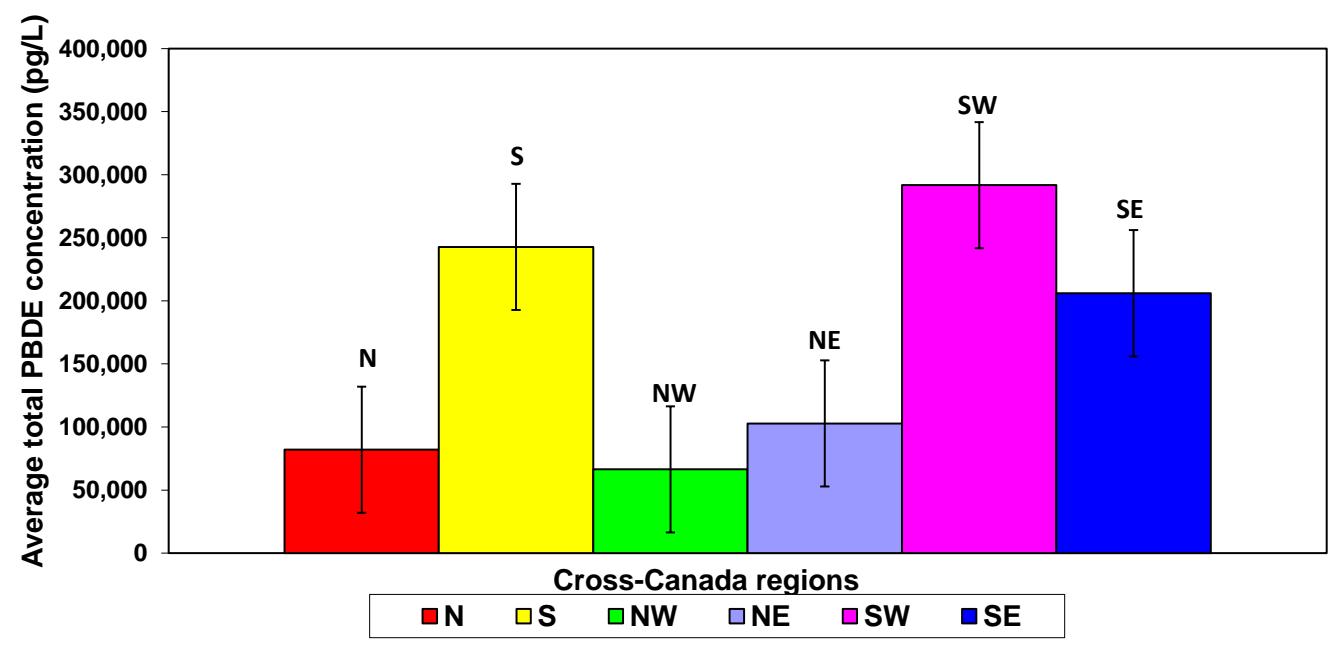

Figure 9. Total PBDE concentrations vs. location in Canada.

\subsection{Consequence of PBDEs Leaching into the Aquatic Environment}

Leachate containing PBDEs may enter water bodies from landfills (Ma et al. 2012), sewage treatment plants (STP), migration from groundwater, and atmospheric deposition (Meyer et al. 2011; Tian et al. 2011; Ma et al. 2012). PBDEs entering the aquatic environment may also depend on whether or not the leachate is treated prior to discharge. In some cases, PBDEs enter the water table without any STP treatment and/or with negligible removal by STPs (Danon-Schaffer, 2010). To illustrate this, an annual estimate of PBDE levels entering the receiving environment from one relatively large jurisdiction is calculated. A constant volumetric flow rate of $1.8 \times 106 \mathrm{~m}^{3} /$ year is assigned 6 . The total PBDE loading from this landfill is $\sim 2.0 \mathrm{~kg} /$ year, estimated from the mass flow for the landfill, the total PBDE concentration in the leachate for the landfill in question and the leachate produced per tonne of solid waste.

\section{Conclusions}

PBDE concentrations were measured in leachate, effluent, and background water samples from across southern and northern Canada. For the leachate samples, PBDE concentrations

\footnotetext{
${ }^{6}$ Obtained from this urban sewage treatment plant. The identity of the STP is confidential. 2006 data.
} 
were primarily determined to be the BDE-209 congener. A similar pattern emerged for the background water samples, with BDE-209 as the major contributor. The concentrations were surprisingly high from the only community in the northern Canada that operates a secondary sewage treatment plant, indicating that the wastewater treatment plant did not efficiently remove PBDEs. More monitoring and duplicate sampling are needed to augment the data set and to study potential temporal trends and other variables. Given this and the analytical uncertainties described previously, it is impossible at this stage to fully define the sources of PBDEs in the northern dumpsites or to be able to interpret them in more detail.

The total PBDE concentrations in samples from landfills in southern Canada varied substantially, from below method detection limit to $867,805 \mathrm{pg} / \mathrm{L}$. The principal congeners BDE-47, -99, -100, -153 -154, -183, -206, -207 excluding BDE-209, contributed less than 40\% of the total PBDEs, while BDE-209 contributed 60 to $92 \%$ of the total for the nine principal BDEs. The large variability in data from different locations presented challenges in interpreting the data. Reproducibility was no doubt affected by different sampling procedures, variable weather, different waste dumping regulations and procedures, different types of waste material disposed at the various sites, and inconsistencies in sub-sampling.

Despite all of the possible factors that influence leachate in a landfill, the variability of the PBDE data, and the non-homogeneous samples containing high amounts of particles, some correlations were found. When the total PBDE concentration was correlated against urban population served by the landfill, there was an overall Pearson coefficient, R, of 0.26. Not surprisingly, there was a clear tendency for landfills in northern Canada to have lower PBDE concentrations than those in southern Canada.

TOC was determined for 21 sites, and 20 sites survived after application of procedural blank correction criteria. Total PBDE and TOC values correlated well only when the samples were restricted to subsets of locations with the highest PBDE levels.

Leachates from Canadian landfills on average show considerably higher PBDE concentrations in leachate than reported in the small number of previous landfill studies published in the open literature, from the U.S., Japan, Sweden, and South Africa.

The data suggest that measurable amounts of PBDEs appear in leachate from landfills, whether in southern or northern Canada. Landfill leachate could therefore provide one source of PBDEs in the environment at large. More work is needed to obtain more accurate data and to determine the processes which lead to leaching, degradation and spread of PBDEs from landfills.

\section{References}

Ikonomou, M. G., Rayne, S., Fischer, M., Fernandez, M. P., \& Cretney, W. (2002b). Occurrence and Congener Profiles of Polybrominated Diphenyl Ethers in Environmental Samples from Coastal British Columbia, Canada. Chemosphere, 46, 649-663.

Ikonomou, M. G., Rayne, S., \& Addison, R. F. (2002a). Exponential Increases of the Brominated Flame Retardants, Polybrominated Diphenyl Ethers, in the Canadian Arctic from 1981 to 2000. Environmental Science \& Technology, 36, 1886-1892. 
Macleod, M., Scheringer, M., Mckone, T. E., \& Hungerbuhler, K. (2010). The State of Multimedia Mass-Balance Modeling in Environmental Science and Decision-Making. Environmental Science \& Technology, 44, 8360-8364.

Ma, J., Qiu, X., Zhang, J., Duan, X., \& Zhu, T. (2012). State of Polybrominated Diphenyl Ethers in China: An Overview. Chemosphere, 88, 769-778.

Devanathan, G. K., Subramanian, A., Sudaryanto, A., Takahashi, S., Isobe, T., \& Tanabe, S. (2012). Brominated Flame Retardants and Polychlorinated Biphenyls in Human Breast Milk from Several Locations in India: Potential Contaminant Sources in a Municipal Dumping Site. Environment International, 39, 87-95.

Rayne, S., Ikonomou, M. G., \& Antcliffe, B. (2003). Rapidly Increasing Polybrominated Diphenyl Ether Concentrations in the Columbia River System from 1992 to 2000. Environmental Science and Technology, 37(13), 2847-2854.

Hites, R. A. (2004). Polybrominated Diphenyl Ethers in the Environment and in People: A Meta-Analysis of Concentrations. Environmental Science \& Technology, 38(4), 945-956.

European Commission, D. E. (2005). Risk Profile and Summary Report for Octabromodiphenyl ether (octaBDE). Dossier prepared for the UNECE Convention on Long-range Transboundary Air Pollution, Protocol on Persistent Organic Pollutants: 22 pp.

Peele, C. (2006). Washington State Polybrominated Diphenyl Ether (PBDE) Chemical Action Plan: Final Plan. Washington State Department of Health, Dept of Ecology Publication No. 05-07-048; Dept of Health Publication No. 334-079: pp 328.

Canada Gazette Part II. (2008). Polybrominated Diphenyl Ether Regulations. SOR/2008-215 to 220 and SI/2008-76 to 77: Pages 1626 to 1715 .

Environment Canada. (2009). State of the Science Report on the Bioaccumulation and Transformation of Decabromodiphenyl Ether. Canada., E.: pp 134.

UNEP-POPS. Stockholm Convention on Persistent Organic Pollutants (06 June 2013). Proposal to list decabromodiphenyl ether (commercial mixture, c-decaBDE) in Annexes A, B and/or C to the Stockholm Convention on Persistent Organic Pollutants: 20 pp.

Alcock, R. E., Sweetman, A. J., Prevedouros, K., \& Jones, K. C. (2003). Understanding Levels and Trends of BDE-47 in the UK and North America: An Assessment of Principal Reservoirs and Source Inputs. Environment International, 29(6), 691-698.

Li, B., Danon-Schaffer, M. N., Li, L. Y., Ikonomou. M. G., \& Grace, J. R. (2012). Occurrence of PFCs and PBDEs in Landfill Leachates from Across Canada. Water Air and Soil Pollution, $223,3365-3372$

Danon-Schaffer, M. N. (2010). Polybrominated Diphenyl Ethers in Landfills from Electronic Waste. Chemical \& Biological Engineering. Vancouver, University of British Columbia. PhD: 394.

de Boer, J. (2004). Brominated Flame Retardants in the Environment - The Price for our 
Convenience? Environmental Chemistry, 1, 81-85

Danon-Schaffer, M. N., Mahecha-Botero, A., Grace, J. R., \& Ikonomou, M. (2013a). Transfer of PBDEs from E-Waste to Aqueous Media. Science of the Total Environment, 447, 458-471.

Danon-Schaffer, M. N., Mahecha-Botero, A., Grace, J. R., \& Ikonomou, M. (2013b). Mass Balance Evaluation of Polybrominated Diphenyl Ethers in Landfill Leachate and Potential for Transfer from E-Waste. Science of the Total Environment, 461-462, 290-301

Francois, V., Feuillade, G., Skhiri, N., Lagier, T., \& Matjeka, G. (2006). Indicating the Parameters of the State of Degradation of Municipal Solid Waste. Journal of Hazardous Materials, B137, 1008-1015.

Sormunen, K., Ettala, M., \& Rintala, J. (2008). Internal Leachate Quality in a Municipal Solid Waste Landfill: Vertical, Horizontal and Temporal Variation and Impacts of Leachate Recirculation. Journal of Hazardous Materials, 160(2-3), 601-607.

Petreas, M., Li, C., Visita, P., Gill, S., Gill, M., \& Garcha, J. (2005). Autoshredder and Electronic Waste as Sources of PBDE Exposures in California. 25th International Symposium on Halogenated Environmental Organic Pollutants and POPs, Toronto, Ontario, Canada, Organohalogen Compounds, Volume 67, p.1012-1015.

Campbell, D. J. V. (1993). Environmental Management of Landfill Sites. Water \& Environment Journal, 7(2), 170-173.

RIS International Ltd. (2003). Information Technology (IT) and Telecommunication (Telecom) Waste in Canada - 2003 Update: Report to Environment Canada. Final Draft. Concord, Ontario: 45.

Puckett, J. B., Westervelt, S., Gutierrez, R., \& Takamiya, Y. (2005). The Digital Dump: Exporting Re-use and Abuse to Africa. Seattle, The Basel Action Network: 43 pp.

UNEP. (2005). E-waste, the Hidden Side of IT Equipment's Manufacturing and Use; Environment Alert Bulletin 5; UNEP: Nairobi, Kenya, 2005; http://www.grid.unep.ch/product/publication/download/ew_ewaste.en.pdf.

DEWA/GRID-Europe.

Grossman, E. (2006). High Tech Trash: Digital Devices, Hidden Toxics and Human Health. Island Press.

Hileman, B. (2006). Electronic Waste: States Strive to Solve Burgeoning Disposal Problem as More Waste Ends Up in Developing Countries. Chemical \& Engineering News, 84(01), 18-21.

US EPA. (2007). Management of Electronic Waste in the United States: Approach Two, Draft Final Report. EPA530-R-07-004b: 75 pp.

Wong, M. H., Wu, S. C., Deng, W. J., Yu, X. Z., Luo, Q., Leung, A. O. W., Wong, C. S. C., Luksemburg, W. J., \& Wong, A.S. (2007). Export of Toxic Chemicals - A Review of the Case of Uncontrolled Electronic-Waste Recycling. Environmental Pollution, 149(2), 131-140. 


\section{MInstitute Macrothink $_{\text {Int }}$}

Environmental Management and Sustainable Development

ISSN 2164-7682

2014, Vol. 3, No. 1

US EPA. (2008). Electronics Waste Management in the United States: Approach I, Final. Office of Solid Waste. Washington, D.C.: pp 31.

Ni, H. G., \& Zeng, E.Y. (2009). Law Enforcement and Global Collaboration are the Keys to Containing E-Waste Tsunami in China. Environmental Science \& Technology, 43(11), 3991-3994.

Alberta Electronics Designation Regulation - Alta Reg. 94/2004.

British Columbia (BC, 2007). British Columbia Recycling Regulation under the Environmental Management Act.

Saskatchewan. (SK, 2007). Saskatchewan Waste Electronic Equipment Regulations under the Environmental Management and Protection Act.

Nova Scotia. (NS, 2008). Solid Waste Resource Management Regulacion. Environmental Management Act.

Ontario. (ON, 2009). Waste Electrical and Electronic Equipment Regulation under the Ontario Waste Diversion Act.

Prince Edward Island. (PEI, 2010). Materials Recycling Regulation under the Environmental Protection Act.

Manitoba. (MB, 2010). Electrical and Electronic Equipment Stewardship Regulation under the Waste Reduction and Prevention Act (WRAP), R17/2010.

Quebec. (QC, 2012). Regulation Respecting the Recovery and Reclamation of Products by Enterprises under the Environmental Quality Act.

Allchin, C. R., Law, R. J., \& Morris, S. (1999). Polybrominated Diphenylethers in Sediments and Biota Downstream of Potential Sources in the UK. Environmental Pollution, 105(2), 197-207.

de Boer, J., Wester, P. G., van der Horst, A., \& Leonards, P.E.G. (2003). Polybrominated Diphenyl Ethers in Influents, Suspended Particulate Matter, Sediments, Sewage Treatment Plant and Effluents and Biota from the Netherlands. Environmental Pollution, 122(1), 63-74.

Chen, S.-J., Feng, A.-H., He, M.-J., Chen, M.-Y., Luo, X.-J., \& Mai, B.-X. (2013). Current Levels and Composition Profiles and Polybrominated Diphenyl Ethers and Alternative Flame Retardants in Surface Sediments from the Pearl River Delta, Southern China: Comparison with Historical Data. Science of the Total Environment, 444, 205-211.

Öman, C. B., \& Junestedt, C. (2007). Chemical Characterization of Landfill Leachates - 400 Parameters and Compounds. Waste Management, 28, 1876-1891.

Camobreco, V., Ham, R., Barlaz, M., Repa, E., Felker, M., Rousseau, C., \& Rathie, J. (1999). Life-cycle Inventory of a Modern Municipal Solid Waste Landfill. Waste Management \& Research, 17, 394-408.

Spalvins, E., Dubey, B., \& Townsend, T. (2008). Impact of Electronic Waste Disposal on 
Lead Concentrations in Landfill Leachate. Environmental Science \& Technology, 42(19), $7452-7458$.

Kiddee, P., Naidu, R., \& Wong, M. H. (2013). Metals and Polybrominated Diphenyl Ethers Leaching from E-waste in Simulated Landfills. Journal of Hazardous Materials, 252-253, 243-249

Oliaei, F. (2005). Flame Retardants: Polybrominated Diphenyl Ethers (PBDEs) Background Paper, Minnesota Pollution Control Agency: $31 \mathrm{pp}$.

Osako, M., Kim, Y. J., \& Sakai, S. (2004). Leaching of Brominated Flame Retardants in Leachate from Landfills in Japan. Chemosphere, 57(10), 1571-1579.

Odusanya, D. O., Okonkwo, J. O., \& Botha, B. (2008). Polybrominated Diphenyl Ethers (PBDEs) in Leachates from Selected Landfill Sites in South Africa. Waste Management. http://dx.doi.org/10.1016/j.wasman.2008.02.011.

Environment Canada. (2009). State of the Science Report on the Bioaccumulation and Transformation of Decabromodiphenyl Ether. Canada., E.: pp 134

Knap, A., Michaels, A., \& Close, H. (1994). Protocols for the Joint Global Ocean Flux Study (JGOFS) Core Measurements. JGOFS Report Nr. 19. Reprint of the IOC Manuals and Guides 29, 170.

Tasaki, T., Takasuga, T., Osako, M., \& Sakai, S. (2004). Substance Flow Analysis of Brominated Flame Retardants and Related Compounds in Waste TV Sets in Japan. Waste Management, 24(6), 571-580

ENVIRON. (2003). Voluntary Children's Chemical Evaluation Program Pilot. Tier 1 Assessment of the Potential Health Risks to Children Associated with Exposure to the Commercial Pentabromodiphenyl Ether Product. CAS No. 32534-81-9. Emeryville, California, ENVIRON Int. Corp.

Stapleton, H. M., Dodder, N .G., Offenberg, J. H., Schantz, M., \& Wise, S. (2005). Polybrominated Diphenyl Ethers in House Dust and Clothes Dryer Lint. Environmental Science \& Technology, 39(4), 925-931.

Rayne, S., \& Ikonomou, M. G. (2002). Reconstructing Source Polybrominated Diphenyl Ether Congener Patterns from Semipermeable Membrane Devices in the Fraser River, British Columbia, Canada: Comparison to Commercial Mixtures. Environmental Toxicology and Chemistry, 21(11), 2292-2300.

Eriksson, J., Green, N., Marsh, G., \& Bergman, Å. (2004). Photochemical Decomposition of 15 Polybrominated Diphenyl Ether Congeners in Methanol/Water. Environmental Science \& Technology, 38, 3119-3125

Söderström, G., Sellström, U., de Wit, C., \& Tysklind, M. (2004). Photolytic Debromination of Decabromodiphenyl Ether (BDE 209). Environmental Science \& Technology, 38, 127-132

Gouin, T., \& Harner, T. (2003). Modelling the Environmental Fate of the Polybrominated 


\section{Ml Macrothink \\ Environmental Management and Sustainable Development \\ ISSN 2164-7682 2014, Vol. 3, No. 1}

Diphenyl Ethers. Environment International, 29, 717-724

Meyer, T., Muir, D. C. G., Teixeira, C., Wang, X., Young, T. M., \& Wania, F. (2011). Deposition of Brominated Flame Retardants to the Devon Ice Cap, Nunavut, Canada. Environmental Science \& Technology, 46, 826-833.

Tian, M., Chen, S.-J., Wang, J., Zheng, X., Luo, X., \& Mai, B.-X. (2011). Brominated Flame Retardants in the Atmosphere of E-waste and Rural Sites in Southern China: Seasonal Variation, Temperature Dependence and Air-Particle Partitioning. Environmental Science \& Technology, 45, 8819-8825.

\section{Copyright Disclaimer}

Copyright reserved by the author(s).

This article is an open-access article distributed under the terms and conditions of the Creative Commons Attribution license (http://creativecommons.org/licenses/by/3.0/). 